\title{
PENGARUH PEMBELAJARAN BIOLOGI BERBASIS PROBLEM BASED LEARNING (PBL) TERHADAP KEMAMPUAN METAKOGNITIF
}

\author{
Andi Asyhari \\ Intitut Agama Islam Negeri Kudus Jawa Tengah Indonesia \\ andyiainkudus@gmail.com
}

\begin{abstract}
ABSTRAK
Problem-based learning (PBL) dalam pembelajaran biologidianggap sebagai salah satu desain pembelajaran innovatif kontekstual, karena mendorong siswa belajar biologi dari masalah-masalah (kasus) nyata yang dijumpai disekeliling kita, dan melatih siswa menjadi pembelajar reflektif (metakognitif). Penelitian ini bertujuan untuk menguji 1) Penerapan pembelajaran biologi berbasis PBL terhadap kemampuan metakognitif siswa, 2) seberapa efektif pengaruh pembelajaran biologi berbasis PBL terhadap kemampuan metakognitif. Penelitian dilakukan di SMA N 01 pecangaan, dengan sampel 33 siswa kelas XI IPA. Desainpenelitian yang digunakanadalah One group single pre-test-post test. Hasil data dianalisis menggunakan uji uji paired simple t-test. Dimana hasil kemampuan metakognitif di peroleh dari hasil angket metakognisi MAI (Metacognition Awareness Inventory). Data hasil penerapan pembelajaran PBL terhadap kemampuan metkognif rata-rata memperoleh penilaian positif dari siswa sehingga dapat dikatakan bahwa penerapan pembelajaran PBL berhasil dilaksanakan dengan baik. Data kemampuan metakognitif mengalami peningkatan sebelum dan sesudah perlakuan sebesar 0,36 (sedang). Peningkatan kemampuan metakognitif tertinggi di dapati dari aspek perencanaan yaitu 0,42 (sedang), dan hasil sebaliknya didapat dari aspek kemampuan metakognitif dalam hal pelaksanaan yang hanya mendapat 0,29 (rendah). Dari hasil analisis data pre-test dan post-test yang di analiasis menggunakan uji paired simple t-test didapati $\mathrm{t}$ tabel (Pada a $=5 \%$ dengan $\mathrm{db}=$ $33-1=32$ diperoleh $t(0.95)(32))$ didapati sebesar 2,04. Oleh karena $t$ hitung $(19,34)$ $>t$ tabel $(2,04)$ maka dapat disimpulkan bahwa terdapat pengaruh yang nyata antara pembelajaran biologi berbasis PBL terhadap kemampuan metakognitif siswa, atau boleh dikatakan bahwa pembelajaran PBL efektif untuk meningkatkan kemampuan metakognitif siswa.
\end{abstract}

Kata kunci: Metakognitif. Problem Based Learning 


\section{ABSTRACT}

Problem-based learning (PBL) in biology learning is considered as one of the design of contextual innovative learning, because it encourages students to learn biology from real problems (cases) encountered around us, and trains students to be reflective (metacognitive) learners. This study aims to examine 1) the application of PBL-based biology learning to students' metacognitive abilities, 2) how effective the influence of PBL-based biology learning on metacognitive abilities. The study was conducted at SMA N 01 pecangaan, with a sample of 33 students in class XI IPA. The research design used was One group single pre-testpost test. The results of the data were analyzed using paired simple t-test test. Where the results of metacognitive abilities were obtained from the results of the Metacognition Awareness Inventory (MAI) questionnaire. Data from the application of $P B L$ learning to the average metacognitive ability received positive ratings from students so that it can be said that the application of PBL learning was successfully implemented properly. Metacognitive ability data has increased before and after treatment of 0.36 (moderate). The highest improvement in metacognitive abilities was found from the planning aspect of 0.42 (moderate), and the reverse results were obtained from the aspect of metacognitive ability in terms of implementation which only got 0.29 (low). From the results of data analysis of pre-test and post-test in analiasis using paired simple test $t$-test found $t$ table (at $a=5 \%$ with $d b=33-1=32$ obtained $t$ (0.95) (32)) found to be $2,04$. Because t arithmetic $(19,34)>t$ table $(2.04)$ it can be concluded that there is a real influence between PBL-based biology learning on students 'metacognitive abilities, or it may be said that PBL learning is effective to improve students' metacognitive abilities.

Keywords: Metacognitive. Problem Based Learning, Biological Learning

\section{PENDAHULUAN}

Akar permasalahan pembelajaran Problem Based Learning (PBL) dapatb erdasarkan pada pergerakan pembelajaran yang progresiv. Yohanes Dewey meyakini bahwapembelajaran harus mampu mengarahkan guru untuk mampu merangsang dan mengelola naluri belajar siswa untuk menuju kearah pembelajaran yang mengarah kanpenyelidikan dan kreatifitas(Delisle, 2002)

'PBL merupakan salah satu metode yang belakangan ini banyak dilakukan untuk peningkatan keterampilan berpikir siswa.Metode ini menuntut aktivitas mental siswa dalam memahami suatu konsep pembelajaran melalui situasi dan masalah yang disajikan pada awal pembelajaran.Masalah yang disajikan pada siswa merupakan masalah kehidupan sehari-hariataukontekstual learning (Sastrawati, 2011) 
PBL pada hakikatnya membantu siswa mengembangkan keterampilan berpikir dan mengembangkan kemampuan dalam memecahkan masalah. PBL menuntut siswa melakukan pemecahan masalah-masalah yang disajikan dengan cara menggali informasi sebanyak-banyaknya, kemudian dianalisis dan dicari solusi dari permasalahan yang ada. Siswa diharapkan menjadi individu yang berwawasan luas serta mampu melihat hubungan pembelajaran dengan lingkungan. Wulandari et al., (2011) menyatakan PBL merupakan cara konstruktif dalam pembelajaran dengan menggunakan permasalahan sebagai stimulus dan berfokus kepada aktivitas pelajar. Metode ini memiliki kecocokan terhadap konsep inovasi bidang pendidikan, terutama dalam hal memperoleh pengetahuan dasar (basic sciences) untuk memecahkan masalah yang dijumpainya. Belajar secara aktif mandiri dengan sajian materi terintegrasi, relevan dengan kenyataan sebenarnya, belajar mampu berpikir kritis, dan mengembangkan inisiatif.

PBL merupakan suatu pendekatan pembelajaran yang menggunakan masalah dunia nyata sebagai suatu konteks bagi siswa, untuk belajar tentang materi pembelajaran tertentu dengan menerapkan proses berpikir kritis dan keterampilan memecahan masalah dalam memperoleh pengetahuan dan konsep yang essensial dalam sebuah pembelajaran menurut Sudirman (2007).

Menurut Arends (2012) PBL merupakan pembelajaran yangmenghadapkan siswa dengan masalah nyata. Mengingat pentingnya kemampuan pemecahan masalah dalam kehidupan saat ini, pendidikan di sekolah sebaiknya memfasilitasi peserta didik untuk mengembangkan kemampuan pemecahan masalah. Siswa membutuhkan kesempatan lebih untuk memecahkan masalah agar menjadi seorang pemecah masalah yang baik.

PBL merupakan salah satu praktek yang paling penting dari konstruktivisme. PBL adalah pembelajar berpusat pada pengajaran yang memastikan peserta didik menjelaskan prinsip-prinsip dan konsep masalah yang berkaitan dengan penelitian dan belajar bagaimana untuk belajar dari masalah-masalah kehidupan nyata. PBL menyediakan lingkungan yang fungsional dimana peserta didik menerima dukungan dari teman sebaya dan guru untuk memberi rekomendasi, dan umpan balik ketika menghadapi masalah, pembelajaran berubah dari satu arah kemulti direktional, dengan masalah nyata dan solusi yang tersedia. Disimpulkan bahwa 
pembelajaran berbasis masalah dapat meningktkan kemampuan metakognitif siswa karena sesuai dengan prinsipnya pembelajaran berbasis masalah merangsang untuk belajar bagimana belajar itu sendiri atau lebih mengarahkan pada kemandirian belajar (Damirel, 2010).

Berdasarkan beberapa pendapat tersebut, PBL pada dasarnya merupakan suatu pendekatan pembelajaran yang menekankan pada keaktifan siswa untuk belajar dari masalah-masalah (kasus) yang dihadapi. Kemandirian siswa dapat dilihat dari kemampuan mengumpulkan informasi yang digunakan dalam investigasi yang diguanakan untuk pemecaham masalah (kasus) yang dipelajari

Metakognitif biasa digolongkan pada kemampuan kognitif tinggi karena memuat unsur analisis, sintesis, dan evaluasi sebagai cikal bakal tumbuh kembangnya kemampuan inkuiri dan kreativitas. Olehkarena itu pelaksanaan pembelajaran semestinya membiasakan siswa untu kmelatih kemampuan metakognitif ini, tidak hanya berpikir sepintas dengan makna yang dangkal (Darma, 2012). Kegiatan metakognitif sangat penting karena dapat melatih siswa untuk berpiki rtingkat tinggi serta mampu merencanakan, mengontrol dan merefleksi segala aktivitas berpikir yang telah dilakukan. Selain itu siswa dapat mengetahui dan menyadari kekurangan maupun kelebihan diri mereka sendiri. Penggunaan proses metakognitif selama pembelajaran, akan membantu siswa agar mampumemperoleh pembelajaran yang bertahan dalam ingatan dan pemahaman siswa. Selanjutnya, Sudiarta (2006) menyatakan bahwa peserta didik hendaknya diarahkan untuk mencapai kompetensi tingkat tinggi melalui.

Flavel (Jonassen, 2000) menjelaskan bahwa metakognitif merupaka kesadaran sesorng dalam belajar, menilai kesukaran, memantau pemahaman, menggunakan strtegi yang tepat, dan menilai kemajuan belajar. Contoh pengetahuan metakognitif yaitu pengetahuan tentang langkah-langkah penelitian, rencana kegiatan dan program kerja, pengetahuan tentang jenis metode, tesyang harus digunakan dan dikerjakan, dan pengetahuan tentang sikap, minat, karakteristik yang harus dikuasai (Nur'aeni et al., 2006). Pengetahuan metakognitif mengarahkan siswa untuk mampu mengatur dan mengelola pengetahuan yang dimiliki sehingga menunjang keberhasilan belajar siswa.

Livingston\& Jenniver (2002) menyatakan bahwa metakognisi terdiri atas 
pengetahuan metakognitif (metacognitive knowledge) dan pengalaman atau regulasi metakognitif (metacognitive experiences or regulation). Pengetahuan metakognitif menunjuk pada diperolehnya pengetahuan tentang proses-proses kognitif, pengetahuan yang dapat dipakai untuk mengontrol proses kognitif. Sedangkan pengalaman metakognitif adalah proses-proses yang dapat diterapkan untuk mengontrol aktivitas-aktivitas kognitif dan mencapai tujuan-tujuan kognitif. Metakognisi sebagai thinking about thinking atau berpikir tentang berpikir. Metakognisi adalah kemampuan berpikir dimana yang menjadi objek berpikirnya adalah proses berpikir yang terjadi pada diri sendiri.

Secara ringkas metakognitif dapat diistilahkan sebagai "thinking about thingking (Daud, 2013). Siswa yang memiliki kemampuan metakognitif mampu mengelola kemampuan yang dimilikinya, memiliki selfmonitoring dan perencanaan, dan memiliki kesadaran kognitif yang baik.Metakognitif memiliki peranan penting dalam mengatur dan mengontrol proses kognitif seseorang dalam belajar dan berpikir lebih efektif dan efisien (Sophianingtyas \& Bambang, 2013). Perlunya kesadaran yang harus dimiliki siswa dalam proses berpikir siswauntuk meningkatkan keterampilan metakognitif. Setiap siswa memiliki kemampuan yang berbeda-beda dalam menanggapi suatu masalah. Beberapa siswa secara sadar memperhatikan masalah yang diberikan dengan menyelesaikannya secara runtut tetapi ada juga siswa yang hanya asal-asalan menjawab ketika dihadapkan pada suatu kasus. Kondisi ini dikarenakan tingkat kesadaran atau tingkat metakognitif yang berbeda

Berdasarkan uraian di atas, maka yang perlu dijawab dalampenelitian ini adalah"bagaimana pengaruh pembelajaran berbasis Problem Based Learning terhadap kemapuan metakognitif siswa danhasil belajarsiswa Dalam penelitian perlu adanya tujuan yang berfungsi sebagai ajuan pokok terhadap masalah yang diteliti, sehingga peneliti akan dapat berkerja secara terarah dalam mencari data sampai pada langkah pemecahan masalah.Adapun tujuan dari penelitian ini adalah: 1) Bagaimana penerapan pembelajaran biologi berbasis problem based learning terhadap kemampuan metakognitif. 2) Bagaimana pengaruh penerapan pembelajaran berbasis problem based learning terhadap kemampuan metakognitif siswa 


\section{METODE PENELITIAN}

Penelitian dilakuakan pada siswa kelas XI IPA di SMA N 01 Pecangaan 2015 dengan menggunankan pendekatan kuantitatif. Desain penelitian yang digunakan adalah pra experimental design. Populasi yang digunakan adalah siswa kelas XI IPA 2 sebanyak 33 siswa. Desain penelitian yang digunakan adalah pre experimental designdengan menggunaka metode "One-Group Pre-testPost-test Design". Hasil penelitian berupa kemampuan metakognitif sebelum dan seudah perlakuan yang diukur menggunakan instrumen lembar angket metakognitif MAI (Metcognitioan awearnes inventory) dan hasil angket respon pembelejaran. Analisis data menggunakanuji paired simple t-test untuk melihat adanya pengaruh pembelajaran berbasis problem based learning terhadap kemampuan metakognitif.

\section{HASIL DAN PEMBAHASAN}

Penelitian mengkaji tentang pengaruh penerapan pembelajaran Problem Based Learning (PBL) terhadap keterampilan metakognitif dilaksanakan di SMA Negeri 1 pecangaan dengan mengambil 1 kelompok sampel yaitu dari kelas XI MIA 1 sebagai kelompok eksperimen. Sebelum dilakukan analisis data pada hasil penelitian, terlebih dulu dilakukan uji prasyarat analisis terhadap data pretest dan posttest dari kelompok eksperimen. Hasil yang diperoleh dari respon siswa terhadap Pembelajaran berbasis PBL terhadap kemampuan metakognitif yang di uji melalu hasil angket respon siswa yang berisi pernyataan yang bernialai respon negatif dan positif di SMA N 1 Pecangaan dengan total 33 siswa di tunjukkan pada tabel berikut ini:

Tabel 1. Hasil angket respon siswa terhadap proses pembelajaran

\begin{tabular}{ccccc}
\hline Kriteria & Pernyataaan & Frekuensi & Ya & Tidak \\
\hline Respon siswa & negatif & 10 point & $8.1 \%$ & $91.9 \%$ \\
& & & & \\
\hline & positif & 11 point & $94.4 \%$ & $5.6 \%$
\end{tabular}


Hasil Tabel 1. Menunjukkan bahwa penerapan pembelajaran berbasis PBL memberikan respon posisitif bagi siswa. Dimana ditunjukkan dari hasil data angket yang memperoleh respon $94 \%$ pada item pertanyaan yang bernilai posistif, dan $91 \%$ pada item pernyatan yang bernilai negatif, Jadi hasil data dari angket respon siswa di atas menunjukkan bahwa pembelajaran PBL lebih mengarahkan siswa untuk belajar aktif secara mandiri dalam hal pemecahan masalah sehingga memebrikan respon positif dalam sebuah pembelajaran

Data hasil angket metakognitif siswa yang di berikan sebelum dan sesudah perlakuan dapat dilihat pada tabel 2. Berikut ini:

Tabel 2. Hasil angket metakognitif sebelum dan sesudah perlakuan

\begin{tabular}{ccccc}
\hline Proses & $\begin{array}{c}\text { Nilai } \\
\text { Rata-Rata } \\
(\%)\end{array}$ & $\begin{array}{c}\text { Nila } \\
\text { Maksimum } \\
(\%)\end{array}$ & Nila & N-gain \\
\hline $\begin{array}{c}\text { Sebelum } \\
\text { perlakuan }\end{array}$ & 63.89 & 75 & 53.3 & 0,36 \\
$\begin{array}{c}\text { Sesduah } \\
\text { perlakuan }\end{array}$ & 76.41 & 83.3 & 69.17 & \\
\hline
\end{tabular}

Hasil angket metakognitif sebelum dan sesudah perlakuan menunjukkan adanya peningkatan sebesar 0,36. Hal tersebut menunjukkan terdapat kecenderungan terjadi peningkatan pada kategori sedang. Hasil angket metakognitif juga dikategorikan pada level kemampuan metakognitif dapat dilihat pada Tabel 3

Tabel 3. Level Metakognitif siswa

\begin{tabular}{clcccc}
\hline $\begin{array}{c}\text { Rentang } \\
\text { sekor (\%) }\end{array}$ & $\begin{array}{c}\text { Level } \\
\text { metakognitif }\end{array}$ & $\begin{array}{c}\text { Sebelum } \\
\text { perlakuan }\end{array}$ & $\begin{array}{c}\text { Rata- } \\
\text { rata }\end{array}$ & $\begin{array}{c}\text { Sesudah } \\
\text { perlakuan }\end{array}$ & $\begin{array}{c}\text { Rata- } \\
\text { rata }\end{array}$ \\
\hline $80-100 \%$ & Sangat tinggi & - & & 8 & 82.29 \\
$70-79 \%$ & Tinggi & 3 & 72.22 & 22 & 75.30 \\
$60-69 \%$ & Sedang & 24 & 64.03 & 3 & 68.89 \\
$45-59 \%$ & Rendah & 6 & 57.22 & - & \\
$>44 \%$ & Sangat rendah & - & & - & \\
\hline
\end{tabular}


Hasil data angket metakognitif siswa yang digolongkan sesuai dengan level kemampuan masing-masing siswa didapati siswa SMA N 1 Pecangaan sebelum perlakuan masuk pada kategori level kemampuan metakognitif pada kategori sedang, namun setelah perlakuan terdapat peningkatan kemampuan metakognitif siswa masuk meningkat pada kategori level tinggi

Angket metakognitif di analisis dari aspek kemampuan metakognitif yaitu:

1)perencanaan, 2) menejeman, 3) monitoring, 4) pelaksanaan, 5) evaluasi. Untuk hasilnya disajikan pada tabel 4.

Tabel 4. Analisis aspek kemampuan metakognitif

\begin{tabular}{llccccc}
\hline \multirow{2}{*}{ No } & \multirow{2}{*}{ Tahap } & \multicolumn{2}{c}{ Sebelum } & \multicolumn{2}{c}{ Sesudah } & \\
\cline { 3 - 6 } & $\begin{array}{c}\text { Rata- } \\
\text { Rata }\end{array}$ & Metakognitif & $\begin{array}{c}\text { Rata- } \\
\text { Rata }\end{array}$ & Metakognitif & N-Gain \\
\hline 1 & Perencanaan & 63.74 & Sedang & 79.22 & Tinggi & 0.42 \\
2 & Menejemen & 63.72 & Sedang & 74.83 & Tinggi & 0.30 \\
& Informasi & & & & & \\
3 & Monitoring & 64.18 & Sedang & 76.62 & Tinggi & 0.34 \\
4 & Pelaksanaan & 61.11 & Sedang & 72.47 & Tinggi & 0.29 \\
5 & Evaluasi & 63.45 & Sedang & 77.65 & Tinggi & 0.38 \\
& $\quad$ Rata-Rata & 63.24 & & 76.16 & & 0.35 \\
\hline
\end{tabular}

Hasil data tabel 4 diatas menunjukkan komponen kemampuan metakognitif, dari mulau perencanaan, manajemen informasi, monitoring, pelaksanaan dan evaluasi. Masing-masing komponen kemampuan metakognitif siswa mengalami peningkatan namun peningktan paling besar terdapat pada komponen perencanaan.

Hasil analisis data di uji menggunakan uji simple paired t-test. Namun sebelum dilakukan analisis data mengunakan uji tersebut terlebih dahulu data harus dianalisis dengan uji homgenitas dan uji normalitas data. Untuk hasil uji normalitas data dapat dilihat pada tabel.5 berikut ini:

Tabel.5 Uji Homogenitas

\begin{tabular}{rrrr}
\hline $\begin{array}{c}\text { Levene } \\
\text { Statistic }\end{array}$ & df1 & \multicolumn{1}{c}{ df2 } & \multicolumn{1}{c}{ Sig. } \\
\hline .191 & 1 & 64 & .663 \\
\hline
\end{tabular}

Hasil uji homogenitas data angket metakognitif didapati nilai signifikasi $0,663>0,05$ maka data dapat dikatakan berbilai homogen. 
Tahap selanjutnya setelah melakukan uji homogenitas data maka akan dilanjutkan uji normalitas data, untuk hasil uji normalitas data dapat dilihat pada tabel.6 berikut ini::

Tabel. 6 Hasil uji normalitas data

\begin{tabular}{lcc}
\hline Data & Sig. & keterangan \\
\hline Pre-test & 0,335 & Normal \\
\hline Post-test & 1,300 & Normal \\
\hline
\end{tabular}

Hasil data angket metakognitif pre-test dan post-test menunjukkan data berdistribusni normal. Dimana $X^{2}$ (hitung) $<X^{2}$ (tabel). Dari uji normalitas data pre-test didapati $0,035<7,81$, maka data angket pre-test dikatakan berdistribusi normal. Untuk data angkte post-test didapati $1,300<7,81$. Maka dapat dikatakan angkte post-test berdistribusi normal

Setelah uji homogenitas dan uji normalitas data maka tahap selanjutnya adalah dilakukan analisis data menggunankan uji paired simple t-test menggunakan spss. Untuk hasil analisis data dapat dilihat pada tabel 7 berikut ini:

Tabel 7. Uji Paired Samples Test

\begin{tabular}{|c|c|c|c|c|c|c|c|c|}
\hline & \multicolumn{5}{|c|}{ Paired Differences } & \multirow[b]{3}{*}{$\mathrm{t}$} & \multirow[b]{3}{*}{$\mathrm{df}$} & \multirow{3}{*}{$\begin{array}{l}\text { Sig. }(2- \\
\text { tailed) }\end{array}$} \\
\hline & \multirow[b]{2}{*}{ Mean } & \multirow{2}{*}{$\begin{array}{c}\text { Std. } \\
\text { Deviation }\end{array}$} & \multirow{2}{*}{$\begin{array}{c}\text { Std. } \\
\text { Error } \\
\text { Mean }\end{array}$} & \multicolumn{2}{|c|}{$\begin{array}{c}5 \% \text { Confidence Interval } \\
\text { of the Difference }\end{array}$} & & & \\
\hline & & & & Lower & Upper & & & \\
\hline $\begin{array}{c}\text { Pair } 1 \text { sebelum perlakuan - } \\
\text { sesudah perlakuan }\end{array}$ & $-1.27273 \mathrm{E} 1$ & 3.74393 & .65174 & 12.76846 & 12.68608 & -9.528 & 32 & .000 \\
\hline
\end{tabular}

Hasil pada tabel diatas menunjukan ada pengaruh yang nyata antara pembelajaran berbasis PBL terhadap kemampuan metakognitif siswa dimana thitung $>\mathrm{t}$ tabel. Dmna Ha diterima $\mathrm{t}(0.95)(32))$ didapati sebesar 2,04t hitung (19, $34)>\mathrm{t}$ tabel $(2,04)$. 


\section{PEMBAHASAN}

Pada penerapan pembelajaran biologi berbasis problem based learning pada dasarnya memeperoleh tanggapan posistif dari siswa, di tunjukkkan dari hasil angket respon siswa terhadap pembelajaran rata-rata memperoleh penilain 90\% masuk pada kategori tinggi, ketercapaian tersebut merupakam indikator keberhasilan penerapan pembelajaran berbasis $\mathrm{PBL}$ dan beroreintasi pada kemampuan metakognitif siswa. Respon positif yang diberikan oleh siswa di tunjukkan dengan tingkat partisispasi siswa dalam proses kegiatan pembelajaran cukup tinggi baik dari segi keaktifan maupun dari segi penerimaan informasi pembelajaran. Penerapan pembelajaran dengan PBL, menawarkan kebebasan siswadalam proses pembelajaran. Panen (2001) menyatakan bahwa pembelajaran PBL memberi kesempatan anak untuk aktif dalam memecahkan masalah secara mandiri dalam menentukan alternatif solusi pemecahan masalah.dan tentunya akan mengahsilkan pembelajaran biologi jauh lebih bermakna sehingga dapat menjadi alternatif proses embelajaran bagi sisiwa. Jadi dari hasil data angket respon siswa di atas menunjukkan bahwa pembelajaran PBL lebih mengarahkan siswa untuk belajar aktif secara mandiri dalam hal pemecahan masalah sehingga memebrikan respon positif dalam sebuah pembelajaran. Oleh sebab itu dapat disimpulkan bahwa pembelajaran biologi berbasis problem based learning berhasil diterapkan di kelas XI IPA SMA N 1 Pecangaan

Hasil angket metakognisi siswa didapati mengalami peningkatan pada kategori sedang setelah mendapatkan perlakuan pembelajaran berbasis PBL Peningkatan terjadi dikarenan pada pembelajaran melatih cara berpikir tingkat tinggi siswa oleh sebab itu terjadi peningkatan kemampuan metakognitif pada diri siswa. Kondisi tersebut juga di dudukung oleh pendapat (Budi, et al. 2013) yang menyatakan bahwa terdapat hubungan antara pembelajaran PBL terhadap kemampuan metakognitif siswa, dimana pembelajaran PBL melatih siswa untuk memecahkan masalah kususnya adalah kemampuan berpikir tingkat tinggi. Sedangkan pada level motakognisi rata-rata yang dimiliki oleh siswa yang diuji cobakan pada mulanya masuk dalam kategori sedang dimana dari hasil keseluruhan 33 siswa sebanyak 24 siswa mendominasi level kemampuan metakognitif masuk dalam level sedang. Namun setelah mengalami perlakuan 
melalui pembelajaran PBL mengalami peningkatan level kemampuan metakognitif pada kategori tinggi. Sebanyak 22 siswa berubah dari level metakognisi sedang naik menjadi level metakognisi tinggi. Hal tersebut juga diperkuat oleh hasil penelitian oleh Downing (2010) yang menyatakan bahwa PBL dianggap mampu secara teori dan idealnya dapat digunakan untuk menumbuh kembangkan kemampuan metakognitif pada diri siswa

Kemampuan metkognitif siswa juga dianalisis berdasarkan komponen aspek kemampuan metakognitif yang terdiri dari:1) perencanaan, 2) menejeman, 3) monitoring, 4) pelaksanaan, 5) evaluasi. Setelah mengalami perlakuan pembelajaran berbasis PBL terjadi peningkatan yang paling besar adalah aspek perencanaan yang mengalami peningkatan sebesar 0 , 42. Kondisi tersebut terjadi dikarenakan dalam pembelajaran PBL memuat langkah yang terakhir adalah evaluasi dimana proses evaluasi merupakan sebuah refleksi terhadap pemecahan masalah yang telah dilakukan. Hasil refleksi pembelajaran akan menstimulus siswa untuk belajar mengevaluasi kekurangan apa saja yang dialami pada saat proses pembelajaran. Siswa akan sadar apa yang dibutuhkan selama proses pembelajaran dan bagaimana memperbaiki kekurangan saat pembelajaran berlangsung. Sehingga siswa akan mampu mengevaluasi proses pembelajaran yang telah dicapai, sehingga siswa akan memiliki kesadaran ketika melakukan sebuah kesalahan ataupun kekurangan pada proses pembelajaran siswa akan mampu merefleksikan apa yang sudah dilakukan dan tentunya siswa akan merencanakan proses pembelajaran agar lebih baik dan efektif. Kondisi tersebut juga di perkuat oleh hasil penelitian Byurkof (2004) yang menyatakan bahwa PBL membantu mengembangkan kemampuan metakognitif khususnya aspek perencanaan

Hasil yang berbeda di tunjukkan pada kemampuan metakognitif aspek pelaksanaan, pada aspek pelaksanaan menunjukkan peningkatan paling rendah dibanding aspek kemampuan metakognitif lainya. Kemampuan metakognitif aspek pelaksanaan mengalami peningkatan sebesar 0,29 dan masuk pada kategori rendah. Kondisi tersebut terjadi karena siswa belum terbiasa atas kesadaran belajar yang dimiliki sehingga pada waktu pelaksanaan pembelajaran siswa belum mampu mengontrol kemampuan kognisi secara baik. Kondisi tersebut juga 
disebabkan oleh menurunya motivasi siswa dalam hal pelaksanaan pembelajaran. Lembar kegiatan siswa memuat terlalu banyak pertanyaan untuk menghubungkan konsep PBL dan metakognitif, sehingga siswa cenderung enggan untuk melaksanakan sesuai yang diharapkan. Dapat dismpulkan bahwa kemampuan metakognitif secara keseluruhan baik perencanaan, menejemen, monitoring, pelaksanaan, evaluasi mengalami peningkatan, jadi dapat dikatakan bahwa penerapan perangkat pembelajaran berbasis PBL dan berorientasi pada kemampuan metakognitif mampu meningkatkan level kemampuan metakognisi siswa,.

Hasil dari angket metakognitif pre-test dan post-test dianalisisi menggunakan uji paired simple t test didapati t hitung sebesar 19, 34 dan t tabel (Pada a $=5 \%$ dengan $\mathrm{db}=33-1=32$ diperoleh $\mathrm{t}(0.95)(32))$ didapati sebesar 2,04. Oleh karena $\mathrm{t}$ hitung $(19,34)>\mathrm{t}$ tabel $(2,04)$ maka Ha diterima. Jadi dapat disimpulkan Ada pengaruh yang nyata antara pembelajaran biologi berbasis PBL terhadap kemampuan metakognitif siswa. Jadi menurut hasil penelitian Budi, et al (2013) menyatakan bahawa pembelajaran PBL merupakan pembelajaran yang mengarahkan siswa untuk untuk berperan aktif dan merangsang berpikir tingkat dan berorientasi pada permasalahan dunianyata. Pembelajaran PBL juga menuntut siswa agar belajar cara berpikir kritis dan keterampilan dalam memecahkan masalah, sehingga pembelajaran PBL lebih mengarhkan siswa untuk meningkatkan kemampuan berpikirnya melalui tahapan-tahapan yang memberikan kekeluasaan dalam membangun pengetahuanya sendiri sehingga dapat terbentuk kemandirian belajara siswa. Melalui proses inilah siswa akan mulai membnetuk dan meningkatkan kemampaun metakognitif yang dimiliki. Tosun \& Erdal (2013) yang menyatakan bahwa PBL lebih efektif dalam meningkatkan level kemampuan metakognitif siswa yang memiliki pengetahuan sains yang lemah. Oleh sebab itu dapat disimpulkan bahwa pembelajaran biologi berbasis PBL berpengaruh nyata terhadap kemampuan metakognitif siswa

\section{SIMPULAN}

Simpulan dari hasil penelitian ini adalah sebagai berikut: 1) penerapan pembelajaran biologi berbasis PBL efektif dalam meningktakan kemmpuan metakognitif siswa.2) pembelajaran biologi berbasis PBL memberikan pengaruh 
yang nyata terhadap kemampuan metakognitif siswa.

Dari kesimpulan diatas terdapat beberapa keterbatasan dalam penelitian yang tentunya menjadi sebuah saran diantaranya adalah: 1) Pembelajaran berbasis PBL memerluka perencanaan yang lebih matang dan pengelolaan waktu yang baik, b) Kelas subjek penelitian yang dilakukan di SMA N 1 Pecangaan hanya terbatas pada satu kelas saja yaitu XI

\section{DAFTAR PUSTAKA}

Arends, R. 2012.Learning to Teach. New York: Mc Graw Hill Companies

Budi, S,M., Abdurrahman.\& Viyanti. 2013. Pengaruh Keterampilan Metakognitif Terhadap Motivasi Dan Hasil Belajar Melalui Model Problem Based Learning (PBL). Jurnal Pembelajaran Fisika. Vol 1, No 5

Biryukov, P. 2004. Metacognitive Aspects Of Solving Combinatorics Problems Beer-Sheva. Kaye College OfEducation Beer-Sheva.

Damirel, M., \& Belma, A. T. 2010. The Effects Of Problem Based Learning On Achievement, Attitude, Metacognitive Awareness And Motivation. Hacettepe Üniversitesi Eğitim Fakültesi Dergisi. Journal of Education. Volume 38

Daud, M. 2013. Deskripsi Kesadaran Metakognitif Siswa Dan Guru Pada Pembelajaran Biologi. Universitas Negeri Gorontalo. Gorontalo

Darma,D,P. 2012. Pengembangan Perangkat Model Pembelajaran Metakognitif Berpendekatan Pemecahan Masalah Dalam Upaya Meningkatkan Aktivitas Dan Prestasi Belajar Matematika Bagi Siswa Smp Kelas VII. Jurnal Pendidikan dan Pembelajaran Matematika. Vol 1, No 1

Downing, K .2010. Problem-based learning and the development of metacognition. As. J. Education \& Learning. Convenor, Institutional Analysis Group. Hong Kong Volume 1 No. 2

Delisle, R. 2002. How to use problem-based learning in the classroom.online. tersedia: http://www.ascd.org/readingroom/books/delisle97book.htm

Jonassen,D. 2000.Toward a DesignTheory of ProblemSolvingTo Appear in Educational Technologi: Research and Developement. Educational Technology Research and Development .Volume 48, No 4 
Livingston., \& Jennifer. A (1997). Metacognition: An Overview. Online.Tersedia:http://gse.buffalo.edu/fas/shuell/cep564/metaco g.html. Di akses (20 Mei 2016)

Pannen, Paulina,2001. Cakrawala Pendidikan. Jakarta.Universitas Terbuka

Sastrawati, E. 2011. ProblemBased Learning, Strategi Metakognisi, dan Keterampilan Berpikir Tingkat Tinggi Siswa. Universitas Jambi. Jambi

Tosun, C \& Erdal, S. 2013. The Effects Of Problem-Based Learning On Metacognitive Awareness And Attitudes Toward Chemistry Of Prospective Teachers With Different Academic Backgrounds. Bartin University Turkey. Australian Journal of Teacher Education. Volume 38 | Issue 3 Article 4.

Wulandari, N.,Sjarkawi.,\& Damris , M. 2011. Pengaruh Problem Based Learning Dan Kemampuan Berpikir Kritis Terhadap Hasil Belajar Mahasiswa. Unifersitas jambi. Jurnal Pedagogi. Volume 1 No. 1. 
